\section{Response to Amir Attaran}

\section{John W. McArthur, Jeffrey D. Sachs, Guido Schmidt- Traub}

Amir Attaran's Policy Forum [1] raises important points on the poor quality of data for some indicators used to measure progress on the Millennium Development Goals (MDGs), but, sadly, uses these findings to draw the wrong conclusions. The evidence he presents on a small number of indicators is partial, and does not justify his conclusion that the MDGs might become a liability and are doomed to fail. Quite the opposite is the case.

Of course the data on the world's extremely poor people are weak, as is just about every other aspect of efforts vis-a-vis the poor. The rich countries dramatically underinvest and make far too little effort in helping to save the poor from dying of malaria and tuberculosis (TB). It is, therefore, no surprise that developing countries and the international system lack the resources and operational support to measure malaria and TB well. Attaran's criticisms in this regard are justified and have been made by many others before him, including many professionals working for the United Nations (UN) system.

The MDGs are a political commitment made by the 189 countries represented at the 2000 Millennium Summit to halve extreme poverty in its many forms by 2015 . The author ignores that such broad outcome goals adopted by world leaders are distinct from the technical question, how to define and measure corresponding indicators, which the UN has been asked to help answer. It is, therefore, inaccurate to blame the UN system for setting goals that are difficult to measure. Goal setting is the prerogative of world leaders, and they have correctly reaffirmed their commitment to the MDGs many times since 2000.

In response, the UN system has set up an active process to review indicators and data on progress toward achieving the MDGs, involving many UN organizations as well as the World Bank and the International Monetary Fund. In recent years, this interagency process has already revised several MDG indicators and issued guidance notes on how data collection can be improved. The author's assertion that the UN "shows a profound disrespect for the scientific process" [1] is wrong and misleading. The UN leadership rightly decided that the heads of state and government convening at the 2005 World Summit should focus their attention on the high-level political decisions needed to strengthen the international framework for security, development, and human rights. On the development side, the greatest priority was to cement the MDGs as operational rather than simply rhetorical targets. The world leaders did not delve into the technical issues of measurement and indicators, but this important work will continue to be addressed by UN statisticians and independent experts. Such experts have indeed been scrutinizing the definition and measurement of these indicators for some time-as did, for example, several of the UN Millennium Project task forces.

Another shortcoming of Attaran's article is that it generalizes incorrectly across the MDGs. It describes some of the toughest measurement challenges (e.g., maternal mortality and malaria), and uses them to paint all the
MDGs with the same brush. In addition to the example of child mortality rates cited in the article, several other MDG indicators can be measured quite well. These indicators include anthropometric measures of malnutrition, primary school enrollment, gender parity in education, and access to basic infrastructure services.

An implication of Attaran's argument is that there should be no goals when measurement is imperfect, as it is in many countries with indicators for maternal mortality. Should world leaders, therefore, not set time-bound goals for reducing maternal mortality? This would be wrongheaded for three clear reasons. First, even with incomplete or missing data, dramatic and verifiable improvements in women's health can be achieved by investing in emergency obstetric care and other known, monitorable, and practical interventions to build and sustain primary health systems. The MDGs provide a major political and operational framework for doing this. Second, the MDGs are already promoting strengthened health systems in low-income settings, and those improved systems are key to ensuring the vital registrations that the author rightly recommends for improving the measurement of maternal mortality. Third, the very adoption of the maternal mortality goal (and others) is provoking greatly increased attention to improvements in data collection from the World Health Organization, the Gates Foundation, the World Bank, academia, and others. The MDGs should not be misunderstood as a static, one-off process.

Attaran misleads the reader when he argues that the MDGs have become "all-encompassing" catch-alls for tenuously related interventions. To say that roads and electricity are falsely linked to achieving the MDGs is incorrect, and suggests a lack of understanding of the integrated nature of development processes. Roads and electricity play a critical role in poverty reduction, access to essential health services, reduction of maternal and child mortality, and a host of other channels directly related to success in achieving the MDGs. Therefore, any strategy to achieve the MDGs needs to include these interventions. The UN Millennium Project described these linkages in the most detailed series of studies on practical approaches to achieving the MDGs that has ever been produced.

We hope that Attaran's key message on improved data collection and interpretation is heard. More and better data are certainly needed on the conditions of the world's poorest and most vulnerable people. However, even in countries with poor data systems, enough is known today to start making the practical and measurable investments in education, health, basic infrastructure, and improved environmental management that are vitally needed to cut, and eventually to end, extreme poverty. Crucially, the MDGs provide the unique framework for prompting the international cooperation that is indispensable to helping poor countries escape the poverty trap, and to benchmarking progress en route. No discussion about indicators and measurementno matter how justified it is-should deflect from the overarching global commitment to the poorest of the poor that world leaders struck at the Millennium Summit in 2000 and reconfirmed at the World Summit in 2005. 
John W. McArthur

Jeffrey D.Sachs (sachs@columbia.edu)

Guido Schmidt-Traub

United Nations Millennium Project

New York, New York, United States of America

Reference

1. Attaran A (2005) An immeasurable crisis? A criticism of the Millennium Development Goals and why they cannot be measured. PLoS Med 2: e318. DOI: 10.1371/journal.pmed.0020318

Citation: McArthur JW, Sachs JD, Schmidt-Traub G (2005) Response to Amir Attaran. PLoS Med 2(11): e379.

Copyright: $\odot 2005$ McArthur et al. This is an open-access article distributed under the terms of the Creative Commons Attribution License, which permits unrestricted use, distribution, and reproduction in any medium, provided the original author and source are credited.

Competing Interests: The authors have declared that no competing interests exist.

DOI: $10.1371 /$ journal.pmed.0020379

\section{Author's Reply}

I am grateful for the reply of Jeff Sachs, John McArthur, and Guido Schmidt-Traub to my article [1,2]. Their reply, written on behalf of the United Nations (UN) Millennium Project, shows that even the leading thinkers of that organization possess beliefs about the Millennium Development Goals (MDGs) that contradict the factual evidence.

On one issue, the UN Millennium Project team agrees with me: progress on the MDGs is sometimes not well measured, such that it is impossible to know if the goals are on track to being fulfilled by their 2015 deadline.

But even on this issue, we disagree on the extent of the problem. The UN Millennium Project team writes that, because my analysis was limited to only the public health MDGs, I based my conclusions on only "the toughest measurement challenges," and "generalize[d] incorrectly across the MDGs" [1]. In their view, if one leaves the difficult health MDGs aside, then "several other MDG indicators can be measured quite well" [1].

To determine whether this assertion is correct, I accessed the UN's own "Data Availability Analysis" [3] for 2005, which takes into account every one of the 48 UN-designated MDG indicators (really 65 indicators in 48 categories). For each indicator, the UN's analysis summarizes the percentage of countries possessing measurements taken in two benchmark years: one year near the starting point of the MDGs (usually 1990) and another year nearer to the present (after 1999). Naturally, it is the difference of this pair of benchmark measurements, taken years apart, which proves whether progress is or is not being achieved for a particular MDG indicator.

The disappointing result of the UN's "Data Availability Analysis" is that, more often than not, the requisite pair of benchmark measurements doesn't exist, such that no factual conclusion about progress can be made. In the best case scenario, there are two indicators with paired benchmark measurements in $98 \%$ of countries. In the worst case scenario, there are 26 indicators-13 times as many-with paired benchmark measurements in none of the countries. Even the median MDG indicator, which is the one indicator most typical of the bunch, has paired benchmark measurements in just $5 \%$ of countries-meaning that the UN does not possess those data for $95 \%$ of countries.
In that context, the UN Millennium Project team is definitely wrong to believe that, health indicators aside, the MDGs "can be measured quite well" [1]. The UN's comprehensive analysis of all MDG indicators shows that, for whatever reason, most are not measured well, not even so rarely as twice a decade.

Why is measurement of the MDGs so generally poor? According to the UN Millennium Project team, the answer is money. They write that "developing countries and the international system," which presumably includes the UN, "lack the resources to measure" the MDGs [1].

However, this belief, too, contradicts the evidence. Concerning the health MDGs, my article recommended expanding the network of demographic surveillance sites (DSS) as the single most efficient way to obtain timely, accurate measurements [2]. According to a recent study of DSS in Tanzania, this costs $\$ 0.01$ per person, per year [4]. Thus, to institute DSS and good quality MDG measurements for the 4 billion poorest people worldwide would cost perhaps $\$ 40$ million annually.

In this context, the UN Millennium Project team's argument that the "international system lacks the resources" to effectively measure the health MDGs is without credibility. The sum of $\$ 40$ million is under $0.1 \%$ of the global foreign aid budget (Organization for Economic Cooperation and Development Development Assistance Committee [OECD DAC]).

Without such steps to measure progress on achieving the MDGs, any claims made for them are necessarily conjectural, rather than objective. The UN Millennium Project team writes that, even without measurement, "the MDGs are already promoting strengthened health systems in lowincome countries" [1] - but regrettably, they fail to furnish evidence of this. They also write that "the very adoption of the maternal mortality goal ... is provoking greatly increased attention to improvements in data collection" [1]. What they fail to mention is that the UN adopted that goal in 1990, and despite 15 years of provoking increased attention, elsewhere the UN Millennium Project team have called the data "unreliable" [5].

I could dispute other unsupported assertions in the reply of the UN Millennium Project team, but choose not to do so because it would distract from this fundamental point: whether to honor the health of the world's poorest or sickest people or to restore the earth's most vulnerable natural environments or to secure human rights for children and women, the UN must demonstrate much greater responsibility than it has in measuring the status of the MDGs. The UN Millennium Project team urges to "cement the MDGs as operational rather than simply rhetorical targets" [1]. I agree this is desirable, and, actually, to place rhetoric ahead of evidence is unethical.

That is why measurement to prove-not just to speculateon the MDGs' operational progress cannot continue to be neglected, and also why the leading intellectuals of the UN Millennium Project err awfully in their judgment when justifying the neglect to date.

\section{Amir Attaran}

University of Ottawa

Ottawa, Ontario, Canada

E-mail:Amir.Attaran@uottawa.ca 
References

1. Sachs JD, McArthur J, Schmidt-Traub G (2005) Response to Amir Attaran. PLoS Med 2: e379. DOI: 10.1371/journal.pmed.0020379

2. Attaran A (2005) An immeasurable crisis? A criticism of the Millennium Development Goals and why they cannot be measured. PLoS Med 2: e318. DOI: 10.1371/journal.pmed.0020318

3. United Nations (2005) Data availability analysis. New York: United Nations. Available: http://unstats.un.org/unsd/mi/techgroup/January2005/Series \%20update\%20status\%20query_FC.xls. Accessed 13 October 2005.

4. Rommelmann V, Setel PW, Hemed Y, Angeles G, Mponezya H, et al. (2005) Cost and results of information systems for health and poverty indicators in the United Republic of Tanzania. Bull World Health Organ 83: 569-577.

5. United Nations Millennium Project (2005) Investing in development: A practical plan to achieve the Millennium Development Goals. New York: Earthscan. 329 p.

Citation: Attaran A (2005) Author's reply. PLoS Med 2(11): e405.

Copyright: $\odot 2005$ Amir Attaran. This is an open-access article distributed under the terms of the Creative Commons Attribution License, which permits unrestricted use, distribution, and reproduction in any medium, provided the original author and source are credited.

Competing Interests: AA has held small contracts or been paid per diem by the World Bank, the United Nations Development Program, and the Roll Back Malaria Partnership in the last five years. None of these agencies were consulted in the development of this manuscript. Research funding was provided exclusively by the Canada Research Chairs program.

DOI: 10.1371/journal.pmed.0020405

\section{Power, Reliability, and Heterogeneous Results}

\section{lan Shrier}

I want to congratulate John P. A. Ioannidis on his thoughtprovoking Essay [1]. I have two comments.

In Corollary 1, he suggests that small sample sizes mean smaller power, and implies that larger studies with thousands of subjects are more likely to be true. I think it is important to stress that if the effect size is large (e.g., very small variance that is seen in physiological studies), then adequate power is obtained with small numbers. Furthermore, some would argue that exposing subjects to research risks unnecessarily (e.g., when fewer subjects would yield sufficient power) is unethical. Since the analysis is based on power, we should remember that larger is not always better.

In Corollary 4, Ioannidis argues that greater flexibility in designs, definitions, etc. means the results are less likely to be true. I agree that replication of all aspects of the study is more likely to yield consistent results, but this does not necessarily mean true results. Since we don't know a priori which methodological details are most appropriate (e.g., dose, timing, etc.), heterogeneous results from different designs is an important source of information and can lead to a new, more in-depth understanding of the subject-and sometimes even paradigm shifts. I agree with the accompanying Editorial [2] to the article that we need to distinguish between the validity of the data and the validity of the authors' conclusions.

lan Shrier

McGill University

Montreal, Quebec, Canada

E-mail:ian.shrier@mcgill.ca

References

1. Ioannidis JPA (2005) Why most published research findings are false. PLoS Med 2: e124. DOI: 10.1371/journal.pmed.0020124

2. PLoS Medicine Editors (2005) Minimizing mistakes and embracing uncertainty. PLoS Med 2: e272. DOI: 10.1371/journal.pmed.0020272
Citation: Shrier I (2005) Power, reliability, and heterogeneous results. PLoS Med 2(11): e386.

Copyright: $\odot 2005$ lan Shrier. This is an open-access article distributed under the terms of the Creative Commons Attribution License, which permits unrestricted use, distribution, and reproduction in any medium, provided the original author and source are credited.

Competing Interests: The author has declared that no competing interests exist.

DOI: 10.1371/journal.pmed.0020386

\section{The Clinical Interpretation of Research}

\section{Stephen G. Pauker}

John P. A. Ioannidis emphasizes the central role of prior probabilities [1]. His conclusion rests on the presumed low probability that a hypothesis was true before the study.

Unfortunately, his formulation relates the post-study probability that the study's conclusion is true to the pre-study odds. The results might have been clearer had he also plotted the relation of odds to probability, a curvilinear relationship, assuming the study carried no information. Further, the various graphs are right-truncated at pre-study odds, $R$, of 1.0 (a probability of 0.5 ), although his examples go as high as $R=2.0$. A positive study must, by definition, increase the likelihood that the hypothesis is true. It might have been clearer had Ioannidis chosen to relate odds to odds or probability to probability; in both cases, a neutral study would produce a straight line along a 45-degree diagonal.

The pre-study to post-study relation can more simply be expressed using the odds-likelihood form of Bayes rule-i.e., the post-study odds equal the pre-study odds multiplied times the likelihood ratio (LR) of the study. Then, the equations for positive predictive value (PPV) become the simple product of $R \times \mathrm{LR}$. For a single unbiased study, $\mathrm{LR}=(1-\beta) / \alpha$. When incorporating study bias, $u$, as defined by Ioannidis, LR $=(1-$ $\beta[1-u]) /(\alpha[1-u]+u)$. For a typical study with $\alpha=0.05$ and $\beta=0.2$ (i.e., with a power of 0.8 ), $\mathrm{LR}=16$. When $R$ is less than $1: 16$ (a probability of 0.0588 ), the post-study odds will be less than one-i.e., the study's hypothesis will be more likely false than true.

For non-Bayesians, statistical significance testing presumes uninformative prior probability-i.e., $R=1$. Then, LR would merely need to exceed one for the study's conclusions to be more likely true than false. At the common significance levels $(\alpha)$ of 0.05 and 0.01 , the requisite study powers would merely need to exceed 0.05 and 0.01 respectively, corresponding to maximum type II error rates $(\beta)$ of 0.95 and 0.99 . Such lax requirements would almost always be met for a published study. Hence, the common belief that the vast majority of studies have valid conclusions would be correct if we can assume that the pre-study odds are truly uninformative. However, as Ioannidis suggests, this is unlikely to be the case.

Two more corollaries might be added. The higher the prestudy odds that the study's hypothesis is true, the lower the requisite power (study size and effect size) required to make the study's findings more likely true than false. When studies are published, the investigator should estimate the pre-study odds and report the LR implied by the observed effect.

From the perspective of an epidemiologist or a statistician, the relevant question is whether the study's hypothesis is true-i.e., is the probability of the hypothesis greater than 0.5 ? For clinicians and their patients, the relevant question is whether a particular strategy should be followed in an 
individual patient or a subset of similar patients. That decision (or recommendation to the patient) will depend on the pre-study likelihood of benefit in that patient and on the relative magnitude of benefits and risks of that strategy, if the diagnosis in that patient is uncertain. For many such decisions, the "more likely true than false" criterion may not be the best decision rule. For serious diseases and treatments of only modest risk, post-study probabilities of considerably less than 0.5 may be sufficient to justify treatment [2].

Ioannidis's provocative Essay is a timely call for careful consideration of published studies. The odds-likelihood formulation suggested herein may be helpful in providing a more intuitive model. Clinicians now need to take it to the next step.

\section{Stephen Pauker \\ Tufts-New England Medical Center \\ Boston, Massachusetts, United States of America \\ E-mail:spauker@tufts-nemc.org \\ References \\ 1. Ioannidis JPA (2005) Why most published research findings are false. PLoS Med 2: e124. DOI: 10.1371/journal.pmed.0020124 \\ 2. Pauker SG, Kassirer JP (1975) Therapeutic decision making: A cost-benefit analysis. N Eng J Med 293: 229-234.}

Citation: Pauker S (2005) The clinical interpretation of research. PLoS Med 2(11): e395.

Copyright: ๑ 2005 Stephen G. Pauker.This is an open-access article distributed under the terms of the Creative Commons Attribution License, which permits unrestricted use, distribution, and reproduction in any medium, provided the original author and source are credited.

Competing Interests: The author has declared that no competing interests exist.

DOI: 10.1371/journal.pmed.0020395

\section{Truth, Probability, and Frameworks}

\section{Jonathan D. Wren}

James T. Kirk: Harry lied to you, Norman. Everything Harry says is a lie. Remember that, Norman: Everything he says is a lie.

Harry Mudd: Now I want you to listen to me very carefully, Norman: I... am... lying.

- Star Trek, the episode "I, Mudd"

Although John P. A. Ioannidis [1] brings up several good points about over-reliance on formal-yet arbitrarystatistical cutoffs and bias against the reporting of negative results, his claim that most published research findings are false is somewhat paradoxical. Ironically, the truer his premise is, the less likely his conclusions are. He, after all, relies heavily on other studies to support his premise, so if most (i.e., greater than $50 \%$ ) of his cited studies are themselves false (including the eight of 37 that pertain to his own work), then his argument is automatically on shaky ground. As mentioned in the PLoS Medicine Editorial [2], scientific studies don't offer truth, per se. Even when studies appear in the best journals, they offer probabilistic assertions. Ioannidis's statement that "the probability that a research finding is indeed true depends on the prior probability of it being true" [1] is really begging the question; this, after all, is the problem. We cannot know such probabilities a priori, and guessing at such probabilities and/or parameters (as he does in his single nucleotide polymorphism [SNP] association example) surely could not be less biased than any statistical test of significance. The key problem in Ioannidis's positive predictive value (PPV) formula to calculate the post-study probability that a relationship is true $(\mathrm{PPV}=[1-\beta] R /[R-\beta R+\alpha]$, where $R$ is the ratio of true relationships to no relationships) is that one can postulate a near-infinite number of non-relationships. Just extending his SNP example, why assume each SNP acts independently? This is not unreasonable, given that schizophrenia is clearly not inherited in a Mendelian pattern. So rather than 99,990 SNPs not being associated with schizophrenia, we have potentially $99,990^{n}$ not associated, where $n$ is the number of potentially interacting SNPs. As $n$ grows, $R$ becomes very small very quickly, and PPV becomes effectively zero. Taken to the extreme, this would imply that all empirical studies are fruitless. One of the most important factors in moving toward the truth, which was not discussed, is fitting discoveries into a framework. Optimally, if a relationship is true, it should have more than one implication, permitting validation from multiple angles. For example, an SNP causally associated with schizophrenia must affect something on the molecular level, whether genomic, transcriptional, post-transcriptional, translational, or post-translational. In turn, these molecules should interact differently with each other, with other molecules within the cell, within a tissue, and/or with the system as a whole. If Norman, the android from Star Trek mentioned in the beginning quote, had been equipped with the capacity to evaluate statements within a framework, he never would have short-circuited as a result of Kirk's paradox. He could have entertained the possibility that either Kirk was lying about Harry or Harry's statement was incomplete (i.e., lying about what?) Similarly, repeatedly re-examining any particular finding to resolve the true/not true paradox via statistical arguments alone can short-circuit our patience. We should instead seek to identify the framework by which implications of the finding can be tested, and I would argue that the more important the finding, the more testable implications it has.

\author{
Jonathan D. Wren \\ University of Oklahoma \\ Norman, Oklahoma, United States of America \\ E-mail:jonathan.wren@ou.edu

\section{References} \\ 1. Ioannidis JP (2005) Why most published research findings are false. PLoS \\ Med 2: e124. DOI: 10.1371/journal.pmed.0020124 \\ 2. PLoS Medicine Editors (2005) Minimizing mistakes and embracing \\ uncertainty. PLoS Med 2: e272. DOI: 10.1371/journal.pmed.0020272
}

Citation: Wren J (2005) Truth, probability, and frameworks. PLoS Med 2(11): e361.

Copyright: $\odot 2005$ Jonathan D.Wren. This is an open-access article distributed under the terms of the Creative Commons Attribution License, which permits unrestricted use, distribution, and reproduction in any medium, provided the original author and source are credited.

Competing Interests: The author has declared that no competing interests exist.

DOI: 10.1371/journal.pmed.0020361

\section{Author's Reply}

I agree with Ian Shrier [1] that, when the effect size is large, adequate power is obtained with small numbers, and it is unnecessary to aim at very large studies. However, most effect sizes probed with statistical testing seem to be small. I also agree that heterogeneity is useful and can offer valuable insights [2]. Sometimes heterogeneity can show us that there are actually two or more research questions, where we thought there was only one [3]. The danger is when heterogeneity is silenced and dismissed in favor of claiming 
consistent results and when heterogeneity is exploited to show only the most spectacular results-unfortunately, this is not uncommon.

As Stephen Pauker [4] also points out correctly, it is useful to think about what the post-study odds are that one is aiming for if a study eventually were to get a "positive" result. Some residual uncertainty is unavoidable in any research question, no matter how strong the evidence. We should learn to live with uncertainty. I also agree that often the credibility level is less than $50 \%$, yet decisions still have to be made. I don't see a problem implementing a very safe and very cheap medical intervention, even if the credibility that it is effective is only $20 \%$. However, it is important to understand and acknowledge that this intervention has a credibility of $20 \%$, while another has a credibility of $70 \%$. I have no objection or preference on how exactly this will be calculated and plotted. Likelihood ratios are also a nice equivalent approach to calculate the probabilities or odds.

I agree with Jonathan D. Wren [5] that it is impossible to be $100 \%$ certain about the exact pre-study odds of truth for any research, mine included of course. However, I argue that we need to start thinking more seriously and consistently about these pre-study odds. In the single nucleotide polymorphism (SNP) association example, one might argue that $1: 10,000$ is not the best choice, but I doubt anyone would choose 1:100 [6]. Some fields may, indeed, have a pre-study odds of zero-these are the "null fields" that I discussed [7]. The differences in the range in pre-study odds are huge in current research, and I am afraid that this is almost completely ignored. I also have no objection about the framework concept. It is nice to see multiple lines of evidence converge. In fact "framework" evidence may be used to formulate more accurate prestudy odds. However, we should be cautious about how this framework is interpreted. We need more empirical data on how scientists try to converge various pieces of biological, epidemiological, and clinical information. I suspect that bias to make things fit, even if they don't, is not negligible.

\section{John P. A. loannidis}

University of loannina School of Medicine

loannina, Greece

E-mail:jioannid@cc.uoi.gr

References

1. Shrier I (2005) Power, reliability, and heterogeneous results. PLoS Med 2: e386. DOI: 10.1371/journal.pmed.0020386

2. Berlin JA (1995) Invited commentary: Benefits of heterogeneity in metaanalysis of data from epidemiologic studies. Am J Epidemiol 142: 383-387.

3. Lau J, Ioannidis JP, Schmid CH (1998) Summing up evidence: One answer is not always enough. Lancet 351: 123-127.

4. Pauker S (2005) The clinical interpretation of research. PLoS Med 2: e395. DOI: 10.1371/journal.pmed.0020395

5. Wren J (2005) Truth, probability, and frameworks. PLoS Med 2: e361. DOI: 10.1371/journal.pmed.0020361

6. Yang Q, Khoury MJ, Friedman JM, Little J, Flanders WD (2005) How many genes underlie the occurrence of common complex diseases in the population? Int J Epidemiol 34: 1129-1137.

7. Ioannidis JPA (2005) Why most published research findings are false. PLoS Med 2: e124. DOI: 10.1371/journal.pmed.0020124

Citation: Ioannidis JPA (2005) Author's reply. PLoS Med 2(11): e398.

Copyright: @ 2005 John P. A. loannidis. This is an open-access article distributed under the terms of the Creative Commons Attribution License, which permits unrestricted use, distribution, and reproduction in any medium, provided the original author and source are credited.

Competing Interests: The author has declared that no competing interests exist.

DOI: 10.1371/journal.pmed.0020398
Did Glycopeptide Use in Animals Result in Hospital Infections of VRE?

\section{Anthony Mudd}

As one of the persons involved with the development of avoparcin for farm animals, I have followed the discussion on vancomycin-resistant enterococci (VRE) and its potential transfer from animals to humans over the past decade. What a pity that the authors of this PLoS Medicine Policy Forum [1] did not reference a recent review by Wassenaar [2] that comprehensively discussed this topic. In this review, evidence is presented to show that VRE infections in humans have actually increased in the European Union since avoparcin was removed from the market. Other data show that wholegenome typing methods separate clinical VRE strains from animal or nonhospitalized human strains.

The conclusion of the Smith et al. article [1] that a correct decision was made to adopt the EU "precautionary principle" and remove avoparcin from the market is surprising, as this is contrary to the opinion of the independent EU Scientific Committee for Animal Nutrition, and since a quantitative risk analysis, as suggested by the authors, could not conclude a relationship between glycopeptide use in animals and incidence of clinical infection in humans.

\section{Anthony Mudd}

Southampton, United Kingdom

E-mail:meonconsultants@aol.com

\section{References}

1. Smith DL, Dushoff J, Morris G Jr (2005) Agricultural antibiotics and human health. PLoS Med 2: e232. DOI: 10.1371/journal.pmed.0020232

2. Wassenaar TM (2005. Use of antimicrobial agents in veterinary medicine and implications for human health. Crit Rev Microbiol 31: 155-169.

Citation: Mudd A (2005) Did glycopeptide use in animals result in hospital infections of VRE? PLoS Med 2(11): e383.

Copyright: $\odot 2005$ Anthony Mudd. This is an open-access article distributed under the terms of the Creative Commons Attribution License, which permits unrestricted use, distribution, and reproduction in any medium, provided the original author and source are credited.

Competing Interests: AM was a consultant advising the International Federation for Animal Health representing the Global Animal Health companies.

DOI: 10.1371/journal.pmed.0020383

\section{The Need of a Neonatal Preparation for Chagas Disease \\ Sergio Sosa-Estani, Jose M. Belizan, Fernando Althabe, Aldofo Rubinstein}

We have read about the efforts and initiatives related to the design of drugs for parasitic diseases in McKerrow's article [1] with interest and expectation. One of the pressing needs in this area is for a neonatal preparation for Chagas disease.

Satisfactory achievements have been made in Argentina in relation to the transmission of the disease by vectors and through blood transfusion $[2,3]$. Vertical transmission is now the great challenge in eradicating Chagas disease. Around 800-1,300 neonates infected with Trypanosmoma cruzi are born every year in our country [4]. Almost $99 \%$ of all births occur in hospital, thus allowing the detection of infants born with parasites immediately after birth. The initiation of treatment of these neonates before they and their mothers leave the hospital is a good strategy to obtain high treatment coverage. 
The later attendance of mothers with their children to healthcare facilities is quite unpredictable and irregular. Also, it is difficult to link information about maternal and neonatal parasitic status obtained at birth with later attendance at other health-care facilities.

It would, therefore, be of great value to have a neonatal preparation for the treatment of Chagas disease. There is currently no neonatal or infant preparation available. Instead, one of the two available adult preparations (nifurtimox or benznidazol) is mashed and diluted at local level in order to be administered to newborns and infants. It is easy to understand the difficulties and uncertainties that these procedures involve.

We hope that in the agenda of the several initiatives mentioned in this article [1] the development of a neonatal preparation for Chagas disease could be considered. It would benefit many infants every year.

Sergio Sosa-Estani (ssosa@msal.gov.ar)

Jose M. Belizan

\section{Fernando Althabe}

\section{Aldofo Rubinstein}

Institute for Clinical Effectiveness and Health Policy

Buenos Aires, Argentina

\section{References}

1. McKerrow JH (2005) Designing drugs for parasitic diseases of the developing world. PLoS Med 2: e210. DOI: 10.1371/journal.pmed.0020210

2. Segura EL, Cura EN, Sosa Estani S, Andrade J, Lansetti JC, et al. (2000) Long-term effects of a Nation-wide control program on the seropositivity for Trypanosoma cruzi infection in young men from Argentina. Am J Trop Med Hyg 62: 353-362.

3. Segura EL, Esquivel ML, Salomón O, Gómez AO, Sosa Estani S, et al. (1994) Participación comunitaria en el Programa Nacional de Control de la Transmisión de la Enfermedad de Chagas. Medicina (B Aires) 54: 610-611.

4. Gurtler RE, Segura EL, Cohen JE (2003) Congenital transmission of

Trypanososma cruzi infection in Argentina. Emerg Infect Dis 9: 29-32.

Citation: Sosa-Estani S, Belizan JM, Althabe F, Rubinstein A (2005) The need of a neonatal preparation for Chagas disease. PLoS Med 2(11): e387.

Copyright: ๑ 2005 Sosa-Estani et al.This is an open-access article distributed under the terms of the Creative Commons Attribution License, which permits unrestricted use, distribution, and reproduction in any medium, provided the original author and source are credited.

Competing Interests: The authors have declared that no competing interests exist.

DOI: 10.1371/journal.pmed.0020387

\section{Placebo: Physician, Heal Thyself}

\section{Arunachalam Kumar, C. Jairaj Kumar}

Kudos to Miller et al. [1] for exposing the seamy side of medical research. No matter how positive the results of drug effectiveness, as demonstrated through against-placebo comparison studies, the fact remains that the ends do not justify the means.

To knowingly and willingly induce a patient to trust in the pharmacotherapeutic effectiveness of a phony drug not only trivializes the patient's intelligence, but also devalues the mentor status of the treating physician.

The role of placebo therapy, though quite dramatic at times, does not sanctify the manner in which large-scale research studies pit one group of falsely guided patients or volunteers against another. The medical and pharmacological world must relegate blind new drug-placebo comparison studies to the back burner. Medical journals, too, have a major role in publishing papers that contain misinformation and that mislead. The psychosomatic pharmacokinetics of drugs can be tested or evaluated through much less dubious means than placebo-based research.

The medical profession has an onus to constantly and continuously present itself as an educated partner of the patient in the treatment of disease and ill health: we are quite positive that not a single volunteer would agree to participate in any placebo-new drug study, if informed of the patently false and fake nature of the research protocols.

There is no denying the fact that placebo therapy has a role in fighting disease, but too much nearly criminal injustice is perpetuated in the form of misinformation in placebo-based research studies. The sooner medical professionals and drug manufacturers proscribe placebo-based research, the better for all.

We congratulate the authors of this Policy Forum [1] for bringing to light this rather dark side of research, and hope that the debate engendered will result in re-establishing the physician as a trusted confidant of the trusting patient.

\section{Arunachalam Kumar (ixedoc@sulekha.com)}

\section{Jairaj Kumar \\ Kasturba Medical College \\ Mangalore, Karnataka, India}

\section{Reference}

1. Miller FG, Wendler D, Swartzman LC (2005) Deception in research on the placebo effect. PLoS Med 2: e262. DOI: 10.1371/journal.pmed.0020262

Citation: Kumar A, Kumar CJ (2005) Placebo: Physician, heal thyself. PLoS Med 2(11): e388.

Copyright: $\odot 2005$ Kumar and Kumar.This is an open-access article distributed under the terms of the Creative Commons Attribution License, which permits unrestricted use, distribution, and reproduction in any medium, provided the original author and source are credited.

Competing Interests: The authors have declared that no competing interests exist. DOI: 10.1371/journal.pmed.0020388

\section{Mental Health Care and Mental Health Legislation in Pakistan: No Mercy for \\ Losers}

\section{Haider Ali Naqvi}

In the Policy Forum by Gilani et al. [1], the authors have quite vividly described the state of mental health care and legislation in Pakistan. Indeed, the situation is one of low awareness and resources, much like other low-income countries in Southeast Asia. Even at the international level, there is deep-seated societal ambivalence toward the mentally ill. The so-called human rights principles have little material effect on the lives of psychiatric patients, and create double standards in the exercise of choice [2].

The promulgation of the new mental health ordinance has, indeed, been a red-letter day in the history of Pakistani legislation. However, how this document translates into real world action remains to be seen. In Pakistan, $70 \%$ of healthcare services are provided by the private sector, and this, too, is mostly curative in nature [3]. According to the World Health Report (2004), 100\% of health-care payments are an out-of-pocket expense for Pakistanis. Most private health care is unregulated. No hospital in Pakistan has Joint Commission 
on Accreditation on Healthcare Organization (JCAHO) accreditation. Anecdotal reports on abuse of individuals who are mentally ill are ubiquitous. It is not uncommon to see patients who are mentally ill chained to their beds. There is poor provision of psychotropic medication in governmentrun hospitals. Contrarily, one sees a cocktail of five medications prescribed by an inadequately trained mental health professional in private practice. Out of 342 registered psychiatrists, hardly 100-150 have adequate training. The Pakistan Medical and Dental Council is the sole body for the proper licensing and credentialing of physicians. The problem lies in the implementation of rules and regulations, rather than their existence. One sees a chain of psychiatric hospitals, claiming to deliver psychiatric care, with no qualified psychiatrists on their panels. There is no legal action taken against these people who blatantly exploit patients with mental illness.

All the major tertiary care centers in Pakistan have allied general medical and anesthesia services, yet the provision of modified electroconvulsive therapy (ECT) is deemed only "preferable" in the new mental health ordinance. Unmodified use of ECT results in serious and potentially life-threatening complications. Similarly, there are other paradoxes in the actual care and legislative protection of people with mental illness. The Federal Authority for Mental Health has played no active role in addressing these glaring inequities since its organization in 2001. Contrarily, there is a risk that it might become a power broker for bureaucracy and ministry officials, rather than serving the real stakeholders.

Essentially, nothing has changed for people with mental illness, except the nomenclature and terminologies. There is still no mercy for people with mental illness in poor and other marginalized communities.

Governmental low health-care spending (less than $1 \%$ of gross national product) should be seen in the context of the bigger geopolitical situation. Countries' major spending is on defense and military armaments. This is in a politically volatile environment, with ongoing border conflicts with neighbors. However, there is a need for strong political will from the government, which oversees the implementation of rules and regulations and protects the rights of people with mental illness.

For a comprehensive solution, an active public-private partnership is required. This requires a unified agenda and commitment from both sectors. Any lasting solution has to address the deep-rooted inequities, ethical misconduct, and micro- and macroeconomic issues.

\section{Haider Ali Naqvi \\ Aga Khan University Hospital \\ Karachi, Pakistan \\ E-mail:haider.naqvi@aku.edu}

\section{References}

1. Gilani AI, Gilani UI, Kasi PM, Khan MM (2005) Psychiatric health laws in Pakistan: From lunacy to mental health. PLoS Med 2(11): e317. DOI 10.1371/journal.pmed.0020317

2. Harding TW (2000) Human rights law in the field of mental health: A critical review. Acta Psychiatr Scand 101: 24-30.

3. Khattak FH (1996) Financing of health sector in health economics and planning in Pakistan. Islamabad: Ad-Rays publishers. pp. 44-61.

Citation: Naqvi HA (2005) Mental health care and mental health legislation in Pakistan: No mercy for losers. PLoS Med 2(11): e397.

Copyright: $\odot 2005$ Haider Ali Naqvi.This is an open-access article distributed under the terms of the Creative Commons Attribution License, which permits unrestricted use, distribution, and reproduction in any medium, provided the original author and source are credited.

Competing Interests: The author has declared that no competing interests exist.

DOI: 10.1371/journal.pmed.0020397

\section{Genetic Research on Nicotine Dependence Will Facilitate Public Health}

\section{Joe Cubells}

W. D. Hall's cogent Research in Translation article [1] on the folly of attempting to use predictive genetic testing in publichealth measures to prevent nicotine dependence is a valuable contribution. Indeed, his arguments against predictive testing can easily be applied to virtually any complex genetic disorder. It is certainly important that we in the medical research community continue to offer such articulate education to clinicians, the press, and society in general.

There is a danger, however, that his arguments will be seized by those who oppose supporting research on the genetics of nicotine dependence and other addictions, to the detriment of public health. For example, Merikangas and Risch [2] have already proposed that addictions and several other complex diseases should be deprived of federal research support in favor of other complex disorders, arguing, "The expensive and laborious tools of molecular genetics [should] be prioritized to those diseases ... that cannot now be treated or prevented with environmental changes [such as] type 1 diabetes, multiple sclerosis, autism and schizophrenia. In contrast, gene hunting for disorders that appear to be highly amenable to environmental modification, such as type 2 diabetes, AIDS, alcohol dependence and nicotine dependence, would have lower priority [for federal research support], even though genes may be involved in their etiology." Those arguments were picked up by right-wing commentators and trumpeted in high-profile lay outlets such as the New York Times. For example, Humphreys and Satel [3] (the latter a resident scholar at the American Enterprise Institute) cite Merikangas and Risch when they conclude, "Some gene research just isn't worth the money ... [because] major cuts in drug-and alcohol-related harm depend not on genes but on choices by policy makers and individual citizens." Thus, the myth that addictive behavior is simply a matter of "choice" is made to appear as if it has solid science behind it, when in my view, the only real rationale for opposing genetic research on disorders related to smoking, drinking, overeating, homosexual sex, and other "sinful" behavior derives from the same strain of religious moralism underlying creationism and intelligent design.

Such arguments miss the most important rationale for genetic research on addictions and other environmentally influenced complex disorders. These conditions deserve continued vigorous support from the National Institutes of Health and other sources because genetic research is a powerful tool for pointing us toward new treatments based on improved understanding of the biology of the disorders. Nicotine dependence is an important case in point because current treatments, which consist of psychosocial interventions, and medication therapies such as nicotine 
replacement and buproprion are, in a word, ineffective: relapse rates following smoking cessation with those strategies, while slightly better than no intervention, usually exceed $80 \%$ at one-year follow-up [4].

Genetic research, by providing suggestive evidence for associations to the genes encoding the gamma-amino butyric acid (GABA) B receptor subunit 2 [5], or the cannabinoid-1 receptor $[6,7]$, has already helped light the way toward potentially more effective interventions for millions who struggle to quit smoking, but repeatedly fail. While predictive testing of risk for nicotine dependence based on those genetic findings is quite useless, it remains to be ascertained whether pharmacogenetic profiling will be useful for identifying those most likely to benefit from specific medications (or for that matter, psychosocial interventions), or who would be at risk for harmful side-effects from an otherwise effective drug. While the potential for such profiling has been hyped up in the popular press just as predictive testing has been, we have only to recall the lives saved by understanding the genetic basis of variation in thiopurine methyltransferase activity, in the context of thiopurine chemotherapy for acute lymphoblastic leukemia [8], to convince ourselves of the importance of studying the genetic basis of all common complex diseases, whether partially amenable to environmental prevention or not.

\section{Joe Cubells}

Emory University School of Medicine

Atlanta, Georgia, United States of America

E-mail:jcubells@genetics.emory.edu
References

1. Hall WD (2005) Will nicotine genetics and a nicotine vaccine prevent cigarette smoking and smoking-related diseases? PLoS Med 2: e266. DOI: 10.1371/journal.pmed.0020266

2. Merikangas KR, Risch N (2003) Genomic priorities and public health. Science 302: 599-601.

3. Humphreys K, Satel S (2005 January 18) Some gene research just isn't worth the money. The New York Times; Section F: 5.

4. Office of the US Surgeon General (2000) Reducing tobacco use: A report of the surgeon general. Centers for Disease Control and Prevention, Office on Smoking and Health. Available: http://www.cdc.gov/tobacco/sgr/sgr 2000/index.htm. Accessed 11 October 2005.

5. Beuten J, Ma JZ, Payne TJ, Dupont RT, Crews KM, et al. (2005) Singleand multilocus allelic variants within the $\operatorname{GABA}(\mathrm{B})$ receptor subunit 2 (GABAB2) gene are significantly associated with nicotine dependence. Am J Hum Genet 76: 859-864.

6. Uhl GR, Liu QR, Walther D, Hess J, Naiman D, et al. (2001) Polysubstance abuse-vulnerability genes: Genome scans for association, using 1,004 subjects and 1,494 single-nucleotide polymorphisms. Am J Hum Genet 69: 1290-300.

7. Zhang PW, Ishiguro H, Ohtsuki T, Hess J, Carillo F, et al. (2004) Human cannabinoid receptor 1: $5^{\prime}$ exons, candidate regulatory regions, polymorphisms, haplotypes and association with polysubstance abuse. Mol Psychiatry 9: 916-931.

8. Weinshilboum R, Wang L (2004) Pharmacogenomics: Bench to bedside. Nat Rev Drug Discov 3: 739-748.

Citation: Cubells J (2005) Genetic research on nicotine dependence will facilitate public health? PLoS Med 2(11): e396.

Copyright: $\odot 2005$ Joe Cubells. This is an open-access article distributed under the terms of the Creative Commons Attribution License, which permits unrestricted use, distribution, and reproduction in any medium, provided the original author and source are credited.

Competing Interests: JC is currently supported by a career development award from the National Institute on Drug Abuse, and collaborates in several ongoing basic research projects in addiction genetics. The opinions expressed here are solely the author's.

DOI: 10.1371/journal.pmed.0020396 